\title{
Aesthetic Principles of the Upper Front Teeth: Application of Golden Proportion (Levin) and Golden Percentage (Snow)
}

\author{
Markovics Emese Rita1, Jánosi Kinga1, Biriș Carmen¹, Cerghizan Diana¹, Horga C11, Bögözi B², lacob \\ Alina² \\ 1 Department of Prosthetic Dentistry and Oral Rehabilitation, University of Medicine and Pharmacy, Tîrgu Mureș, Romania \\ 2 Department of Oro-Maxillofacial Surgery, University of Medicine and Pharmacy, Tîrgu Mureș, Romania
}

\begin{abstract}
Objective: The objective of our work is to examine the presence of the much-discussed golden proportion provided by Levin, and of the golden percentage (Snow), on the widths of maxillary anterior teeth, by measurements made on digital images.

Material and method: The material of this study consists of digital photographs taken of subjects with natural and esthetic teeth. We took photos of 68 subjects (35 women and 33 men), between 19 and 26 years. Using a computer program, we made the necesarry measurements, then we made the appropriate calculations of the above theories.

Results: The golden proportion between the lateral and central incisor occurs in a higher proportion than between the canine and the lateral incisor. The values obtained by analyzing the golden proportion differ slightly from those proposed by Snow.

Conclusions: The frequency of the golden proportion is not significant for the groups of teeth mentioned. With small modifications and taking into consideration ethnic differences, Snow's golden percentage is more valid and applicable than Levin's golden proportion is.
\end{abstract}

Keywords: golden proportion, golden percentage, front teeth

Received: 16 January 2013

\section{Introduction}

The golden section or ratio is known as the basis for perfect beauty. It can be found in the ancient Egyptian and Greek architecture, and also in the Medieval and Renaissance art. Leonardo da Vinci, who also examined this ratio, discovered it in the human body too, and named it Divine Proportion.

The golden ratio is expressed numerically through an irrational number, and it is marked with the letter $\phi$ (phi) $\approx 1.618$. Two parts of the whole ( $\mathrm{a}$ and $\mathrm{b}, \mathrm{a}>\mathrm{b}$ ) are in proportion to each other according to the golden ratio, if the whole $(a+b)$ is in proportion to the bigger part $(a)$, as is the bigger one to the smaller part (b) [1-8].

$$
a: b=(a+b): a=1.618
$$

Lombardi (1973) was the first who examined the application of the golden ratio in dentistry [9]. Levin (1978) determined that from frontal view, the apparent surfaces of the upper frontal teeth are in proportion according to the principle of the golden section: the width of the central incisor (CI) with the width of the lateral incisor (LI), and the width of the lateral incisor with the width of the canine (C) [10]. This theory is also supported by Shoemaker and Ricketts [11,12]. Due to Levin's observation, the golden section was introduced into several course-books as an es-

Correspondence to: Emese Markovics

E-mail: emesemarkovics@gmail.com thetic principle for the restoration of frontal teeth. As a consequence, this method was accepted and recommended by many other authors [13-16]. There are also authors who contradicted the validity of the golden ratio of the upper frontal teeth in different studies. As an alternative, there are other principles for the implementation of esthetic restoration in the frontal zone: the golden percentage [24], Recurring Esthetic Dental [19], Preston's Proportion [17].

According to the method of the golden percentage, recommended by Snow, after examining the teeth from a frontal view, we put in proportion the apparent width of a single tooth to the width of the six upper frontal teeth. This gives us the following results: C 10\%, LI 15\%, CI 25\%, CI $25 \%$, LI 15\%, C 10\% [24].

This method is also mentioned by other authors by the planning of an esthetic frontal zone [25,26].

\section{Materials and method}

We took pictures with a Canon PowerShot A620 digital camera (7.1 MPx) of 68 subjects (33 men and 35 women) with natural esthetic teeth. Their ages varied between 19 and 26 years. The subjects were told that their participation in the survey was completely voluntary. The study protocol was explained and written informed consent was received from each person before clinical examination. Excluding criteria were: surgical or orthodontic treatments, periodontal treatments, prosthesis in the region of the upper teeth, dento-alveolar trauma, dentofacial deformities, or any other asymmetry in the superior arch: spac- 
Table I. Repartition of the golden ratio based on gender

\begin{tabular}{lcccc}
\hline Golden ratio & Gender & Right & Left & $\begin{array}{c}\text { Percentage } \\
\text { difference }\end{array}$ \\
\hline Lateral incisor / Central incisor & $\mathrm{M}+\mathrm{F}$ & $17.64 \%$ & $14.7 \%$ & 2.94 \\
Lateral incisor / Central incisor & $\mathrm{M}$ & $6.06 \%$ & $18.18 \%$ & 12.12 \\
Lateral incisor / Central incisor & $\mathrm{F}$ & $28.57 \%$ & $11.42 \%$ & 17.15 \\
Canine / Lateral incisor & $\mathrm{M}+\mathrm{F}$ & $7.35 \%$ & $5.88 \%$ & 1.47 \\
Canine / Lateral incisor & $\mathrm{M}$ & $3.03 \%$ & $9.09 \%$ & 6.06 \\
Canine / Lateral incisor & $\mathrm{F}$ & $11.42 \%$ & $2.85 \%$ & 8.57 \\
\hline
\end{tabular}

ing, rotation, tooth inclination. The photo was taken with the head in the natural position, so that the bipupilar line was parallel to the floor, and the median was adjusted to the center of the camera lens. Patients were asked to smile when we took the photos. The patients held a line in front of their faces, which appears in the photos. The photos were downloaded to a computer, and using the program Adobe Photoshop CS5, we performed the necessary measurements. We measured the number of pixels per $\mathrm{cm}$, using the "zoom" function of the program, so that we could measure the apparent mezio-distal width more accurately. For each patient we measured the width of each of the 6 crowns: from canine on the right side ( $\mathrm{r}$ ) to the one on the left side(l): Cr, LIr, CIr, CIl, LIl, Cl.

The null hypothesis of our work is that the golden section (Levin) and the golden percentage (Snow) are not present in most of the analyzed cases.

After obtaining the results, the calculations were performed corresponding to the aforementioned theories (golden ratio and golden percentage). The resulting data was analyzed with the Microsoft Excel and SPSS 16 programs. For processing the data we used the paired samples $T$ test to analyse the differences in the golden number which appear between the left and right side for each subject's frontal teeth. We performed the chi squared test to examine the differences between the male and female group.

We studied the golden number on the scale of Preston, and the results were considered valid in the interval of $0,61-0,63[18,19]$. The calculation of the golden ratio: we divided the apparent width of LI with the apparent width of the CI, and the result was multiplied with 100 . If the resulting numbers were between $0.61-0.63$ (61\% to $63 \%)$

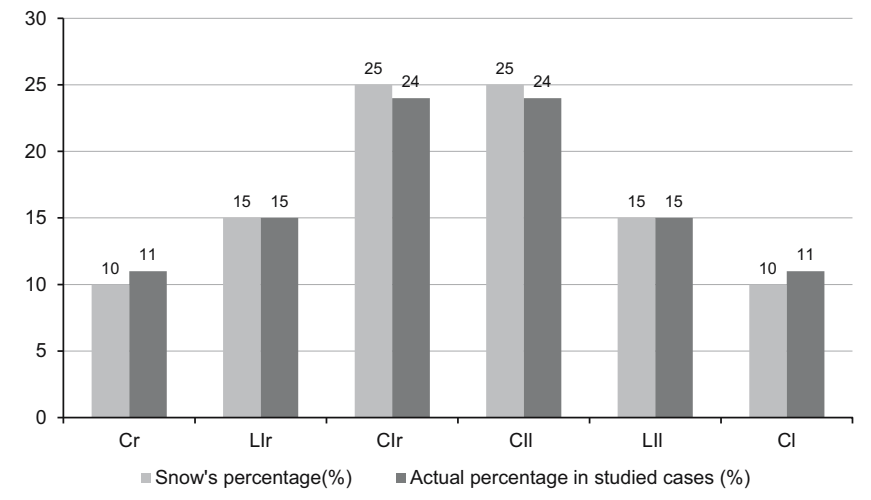

Fig. 1. Comparison of the percentage in studied cases and Snow's percentage

$\mathrm{M}=$ Male; $\mathrm{F}=$ Female; $\mathrm{Cr}=$ right Canine; LIr = right Lateral Incisor; $\mathrm{Clr}=$ right Central Incisor; $\mathrm{Cll}=$ left Central Incisor; $\mathrm{LII}=$ left Lateral Incisor; $\mathrm{Cl}=$ left Canine

we considered they denote the golden section. After that, we made the same measurements in the cases of $\mathrm{C}$ and LI.

The calculation of the golden percentage: the apparent width of each tooth (CI, LI, C, on the left and right side) was divided by the apparent total width of the 6 crowns, and was multiplied by 100 . If the percentages from these 6 crowns were $10 \%, 15 \%, 25 \%, 25 \%, 15 \%, 10 \%$ they adapt to each other according to the theory of the golden percentage.

\section{Results}

The golden section, based on the scale of Preston (0.61$0.63)$, appeared in $30.88 \%$ of the cases between the width of the lateral and central incisors, and in $11.76 \%$ of the cases between the width of the lateral incisor and canine.

In $14.7 \%$ of the cases, we found the golden section on the left side between the LI and CI. Between LI and C on the left side the golden section appeared only in 5.88\% of the cases. In the case of teeth on the right side of the golden section appeared between the lateral incisors and the central incisors in $17.64 \%$ and between canines and lateral incisors in $7.35 \%$.

There was no statistical difference regarding the golden section between the right and the left side $(\mathrm{p}=0.123)$. Also, the chi squared test showed no significant differences between males and females $(\mathrm{p}=0.061)$.

Based on our calculations, the golden section between the LI and CI on the left side in case of men was $18.18 \%$,

Table II. Repartition of the golden percentage based on gender

\begin{tabular}{|c|c|c|c|c|c|c|c|}
\hline Teeth & $\mathrm{Cr}$ & LIr & Clr & Cll & LII & $\mathrm{Cl}$ & Total width \\
\hline Total width $\mathrm{F}+\mathrm{M}$ & 291.35 & 386.03 & 605.23 & 602.06 & 374.41 & 276.8 & 2535.88 \\
\hline Total average & 4.28 & 5.68 & 8.90 & 8.85 & 5.51 & 4.07 & 37.29 \\
\hline Average percentage in studied cases & $11 \%$ & $15 \%$ & $24 \%$ & $24 \%$ & $15 \%$ & $11 \%$ & \\
\hline Total width $\mathrm{F}$ & 136.05 & 187.53 & 305.17 & 302.47 & 180.03 & 127.67 & 1238.92 \\
\hline Average width $\mathrm{F}$ in studied cases & 3.78 & 5.21 & 8.48 & 8.40 & 5.00 & 3.55 & 34.41 \\
\hline Average percentage $\mathrm{F}$ & $11 \%$ & $15 \%$ & $25 \%$ & $24 \%$ & $15 \%$ & $10 \%$ & \\
\hline Total width $\mathrm{M}$ & 155.3 & 198.5 & 300.06 & 299.59 & 194.38 & 149.13 & 1296.96 \\
\hline Average width $M$ in studied cases & 4.85 & 6.20 & 9.38 & 9.36 & 6.07 & 4.66 & 40.53 \\
\hline Average percentage $\mathbf{M}$ & $12 \%$ & $15 \%$ & $23 \%$ & $23 \%$ & $15 \%$ & $11 \%$ & \\
\hline
\end{tabular}


and in the case of women was $11.42 \%$. In $9.09 \%$ of men and $2.85 \%$ of women, we could identify the golden section between $\mathrm{C}$ and $\mathrm{LI}$ on the left side. The golden section rate between $\mathrm{LI}$ and $\mathrm{CI}$ on the right side was $6.06 \%$ in men and $28.57 \%$ in women. The golden section rate in the case of $\mathrm{C}$ and $\mathrm{LI}$ on the right side was $3.03 \%$ in men and $11.42 \%$ in women (Table I).

The average proportion values were: on the right side: $\mathrm{C} /$ $\mathrm{LI}=0.76(\mathrm{SD} \mathrm{0.105}), \mathrm{LI} / \mathrm{CI}=0.64(\mathrm{SD} 0.066)$ and on the left side $\mathrm{C} / \mathrm{LI}=0.74$ (SD 0.097), $\mathrm{LI} / \mathrm{CI}=0.062$ (SD 0.072).

The golden percentage examination results show an average value for central incisor of $23 \%$ for men and 24 $25 \%$ for women, slightly less than the $25 \%$ proposed by Snow. The lateral incisor average value was $15 \%$ for men and women, which coincides with Snow's proposed value. In the case of the canine, the average was $11-12 \%$ for men and $10-11 \%$ for women, which is slightly more than the $10 \%$ proposed by the same theory (Table II).

It seems that the widths of the central incisors are lower, and the widths of canines are slightly greater than the values indicated by Snow (Figure 1).

\section{Discussion}

The golden section occurs in a higher proportion between the LI and CI, than between the C and the LI. We discovered it in the highest proportion in women $(28.57 \%)$ between the lateral incisor and the central incisor on the right side. Fayyad noted the highest proportion (38.2\%) in men between the CI and LI [21]. Murthy obtained the highest result (25\%) between C and LI on the left side [22].

Also from the calculation of average proportions of teeth groups we conclude that the proportions between the $\mathrm{LI}$ and $\mathrm{CI}$ are closer to the golden number, than those of the $\mathrm{C}$ and LI.

According to Mahshid, the average proportion of canine and lateral incisor is 0.84 , and of the lateral incisor and central incisor is 0.67 , so, in comparison with this study, they found a greater difference between the proportion of teeth and the golden section [20]. Therefore these results do not prove that the golden section would be the average proportion characteristic for this group of teeth.

The results obtained by analysing the golden percentage differ slightly from the values proposed by Snow [24]. Our results are consistent with the studies conducted by Fayyad [21] and Murthy [22].

\section{Conclusions}

In the natural and esthetic dentition, the width of maxillary anterior teeth does not follow the rules of the golden section. Thus, the golden section is not a common factor in esthetic smiles.

In most of the cases, the canine is not within golden section with the lateral incisor, and the central incisor with the lateral incisor.

Our results suggest that there is no significant difference between the width of teeth on the left and right side.
The values of Snow's theory of golden percentage were not fully confirmed in this study. However, with small modifications, Snow's golden percentage is more valid and applicable than Levin's golden section.

Thanks to the wealth of nature, aestetics can not be constrained within mathematical limits in dentistry. It is difficult to standardize aesthetics, because the perception of beauty varies from person to person. Beside the pursuit of certain fundamental theories we must take into account the dental and facial characteristics of the patients, the variety of proportions of natural teeth and the individual estimation of aesthetics as well.

\section{References}

1. Samorodnitzky-Naveh GR, Geiger SB. Patient's satisfaction with dental esthetics. JADA. 2007;138(6):805-808.

2. Bîclesanu C, Valeriu I, Pangică A. Importanța esteticii în restaurarea funcției fizionomice a pacientului. Revista Română de Stomatologie. 2007; LIII(4):176-180.

3. Petre A, lonită S, Trăistaru T. Criteriile estetice in medicina dentara consemnate in literatura de specialitate. Revista Română de Stomatologie. 2011;LVII(4):278-286.

4. Tin-Oo M, Saddki N, Hassan N. Factors influencing patient satisfaction with dental appearance and treatments they desire to improve aesthetics. BMC Oral Health. 2011;11:6.

5. Akarslan ZZ, Sadik B, Erten H, Karabulut E. Dental esthetic satisfaction, received and desired dental treatments for improvement of esthetics. Indian J Dent Res. 2009;20:195-200.

6. Magne P, Belser U. Bonded porcelain restorations in the anterior dentition: A Biomimetic Approach. Quintessence Pub. Co.,Germany, 2002;58-59.

7. Vadachkoriia NR, Gumberidze NSh, Mandzhavidze NA. Golden proportion and it's application to calculate dentition. Georgian Med News. 2007; 142:87-94.

8. Constantinescu MV, Feinmann PB, Hutu E, et al. Utilizarea numărului de aur în medicina dentară. Revista Romana de Stomatologie. 2006;LII(1-2): 71-76.

9. Lombardi RE. The principles of visual perception and their clinical application to denture esthetics. J Prosthet Dent. 1973;29:358-382.

10. Levin El. Dental esthetics and the golden proportion. J Prosthet Dent. 1978;40:244-252.

11. Shoemaker WA. How to take the guesswork out of dental esthetics and function. Part III. Fla Dent J. 1987;58:35-39.

12. Ricketts RM. Divine proportion in facial esthetics. Clin Plast Surg. 1982;9(4):401-22.

13. Rosenstiel SF, Land MF, Fujimoto J. Contemporary fixed prosthodontics. 3rd ed. St. Louis: CV Mosby, 2001, 598-599.

14. Rufenacht CR. Fundamentals of esthetics. 2nd ed. Chicago: Quintessence, 1990.

15. Shillingburg HT, Hobo S, Whitsett LD, Jacobi R, Brackett SE. Fundamentals of fixed prosthodontics. 3rd ed. Chicago: Quintessence, 1997, 422-423.

16. Goldstein RE. Esthetics in dentistry. 2nd ed. Hamilton, ON: BC Decker, 1998, 189-191.

17. Preston JD. The golden proportion revisited. J Esthet Dent. 1993; 5:247251.

18. Gillen RJ, Schwartz RS, Hilton TJ, Evans DB. An analysis of selected normative tooth proportions. Int J Prosthodont. 1994;7:410-417.

19. Ward DH. Proportional smile design using the recurring esthetic dental (RED) proportion. Dent Clin North Am. 2001;45:143-154.

20. Mahshid M, Khoshvaghti A, Varshosaz M, Vallaei N. Evaluation of "golden proportion" in individuals with esthetic smile. J Esthet Restor Dent. 2004; 16:185-192.

21. Fayyad MA, Jaman KD, Aqrabawi J. Geometric and mathematical proportions and their relations to maxillary anterior teeth. J Contemp Dent Pract. 2006;7:1-10.

22. Murthy BV, Ramani N. Evaluation of natural smile: Golden proportion, RED proportion, Golden percentage. J Conserv Dent. 2008;11:16-21.

23. Levin El. The updated application of the golden proportion to dental aesthetics. Aesthetic dentistry today. 2011;5(3):22-27.

24. Snow SR. Esthetic smile analysis of anterior tooth width: The golden percentage. J Esthet Dent. 1999;11:177-184.

25. Morley J. Smile design specific considerations. J Calif Dent Assoc. 1997;25:633-637.

26. Ahmad I. Geometric considerations in anterior dental aesthetics: restorative principles. Pract Periodontics Aesthet Dent. 1998;10:813-822. 